\title{
The perceived impression of public on Genetic Engineering
}

\author{
S Islam', S Islam²
}

\begin{abstract}
Genetic engineering (GE) - also known as genetic modification (GM), is the direct manipulation of an organism's genome using biotechnology. The field of genetic engineering deals with different kinds of alterations done on plants, animals and microorganisms and it has many applications in different sectors such as medicine, research, industry and agriculture. As GM plays an important role on food and agriculture, treatment of hereditary diseases, waste decomposition . all of which affects our lives, it concerns the geneticists and the general people alike.
\end{abstract}

Objectives: The perceived impression of the mass population on Genetic engineering and analyzing how much it is accepted in today's society.

Methodology: This descriptive cross sectional study was conducted from July to December 2013. Structured questionnaire was used to collect data from the concerned public around the world by using the site http://kwiksurveys.com/. [Link to this survey

Results: Globally 67 people took the survey through web site and all of the participants were above 18 years of age and consisted of people who had little $(53.73 \%)$ or no knowledge on GE $(2.99 \%)$ and also people who were aware (31.34\%) or had a deep knowledge (11.94\%) of it.

In this study $32.35 \%$ of people found the modification of genes Unethical but necessary and $30.88 \%$ of people found it Ethical and very useful. This showed that the majority of the people had accepted GE. When used for a good cause GE is morally acceptable to people (73.13\%)

Conclusion: This research has provided us a brief idea about the mental mental attitude or psychology of the respondents regarding the acceptance of GE in the society. This study showed that majority of the people belief GE will be beneficial some are still against it.

Key words: Genetic engineering, perceived impression, public. http://kwiksurveys.com/s.asp?sid=0d392dzgagjkxtv283552]. Statistical analysis was done with SPSS version 22.

1 Saba Islam 3rd Year Dept. of Microbiology North South University

\section{Saad Islam 1st Year Dept. of Computer Science \& Engineering North South University}

Correspondence
Saba Islam
3rd Year
Dept. of Microbiology
North South University
Email: saba.islam@gmail.com

Correspondence

Dept. of Microbiology North South University
Email: saba.islam@gmail.com intervention has actively manipulated what the bacteria actually is. No doubt there are advantages and disadvantages.

GE is changing the face of agriculture and try to make the solution to world hunger. Genetically engineered foods have made their way onto our grocery shelves. According to its developers, the technology of GE was created to improve food production, reduce the use of pesticides and herbicides, and increase yields to feed our growing world.

Disease could be prevented by detecting people/plants/animals that are genetically prone to certain hereditary diseases. Also, infectious diseases can be treated by implanting genes that code for antiviral proteins specific to each antigen.

Animals and plants can be 'tailor made' to show desirable characteristics. Genes could also be manipulated in trees for example, to absorb more $\mathrm{CO}_{2}$ and reduce the threat of global warming.

GE could increase genetic diversity, and produce more variant alleles which could also be crossed over and implanted into other species. It is possible to alter the genetics of wheat plants to grow insulin for example. But a growing number of scientists, physicians, clergy, consumers, business leaders and governments all over the world are voicing concerns over the proliferation of these GE because of some possible eventualities and disadvantages.

Nature is an extremely complex inter-related chain consisting of many species linked in the food chain. Some antagonist believe that introducing genetically modified genes may have an irreversible effect with consequences yet unknown. Also GE borderlines on many moral issues, particularly involving religion, which questions whether man has the right to manipulate the laws and course of nature.

That's why now a days GE has become one of the most controversial topics in Science as it became an integral part of engineering, biotechnology, and economics. Its ethical issues concern the geneticists and the public alike.

Therefore the focus of our study was on the perceived impression of the mass population on GE and wanted people to be aware of the real picture and also to get the insight of other people on GE.

\section{Methodology}

This descriptive cross sectional study was conducted from J uly to December 2013.

We conducted a survey of a representative sampling of the concerned public around the globe by using the site http://kwiksurveys.com/ [Link to our survey http://kwiksurveys.com/s.asp?sid= 0d392dzgagjkxtv283552]. Anyone above 18 years of age and who had little or no knowledge on GE and also who were well aware of it could be participated in this Study. We had designed a questionnaire with 
different types of questions so as to get a range of useful data which helped us to fulfil our research objectives. The questionnaire consisted of 16 questions of which 14 questions are open ended, and the remaining 2 are given with Multiple Answers. We used the standard search engine Google and referred to valid Journals, abstracts and articles on GE which has been cited and the information can be found on the Reference list. Statistical analysis was done with SPSS version 22.

Results : Sixty seven ( 67 ) people from all around the globe who were all above 18 years of age and have expressed their thoughts on GE through their answers .Most of the respondents 37 (55.22) were from Asian countries and only one respondent from Antarctica also (fig 1).

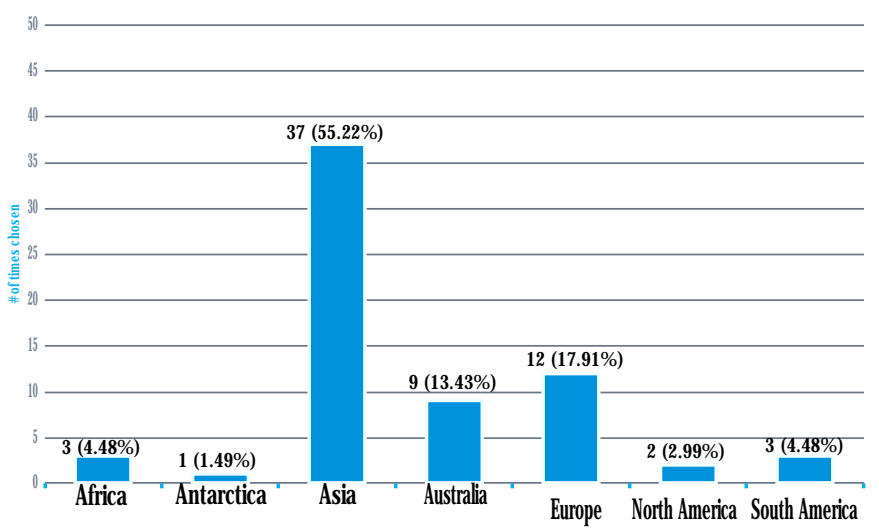

Fig 1: Global participation of the Respondents

This study showed the level of understanding of the respondents on Genetic engineering. Among the representative sample of 67 respondents most of them were aware of GE. Most of the respondents $36(53.73 \%)$ had at least some idea about what genetic engineering is, $21(31.34 \%)$ of the respondents claimed to know what it is, $8(11.94 \%)$ of the respondents said they had a deep understanding of the field and only $2(2.99 \%)$ respondents said they had never been introduced to GE (Fig 2).

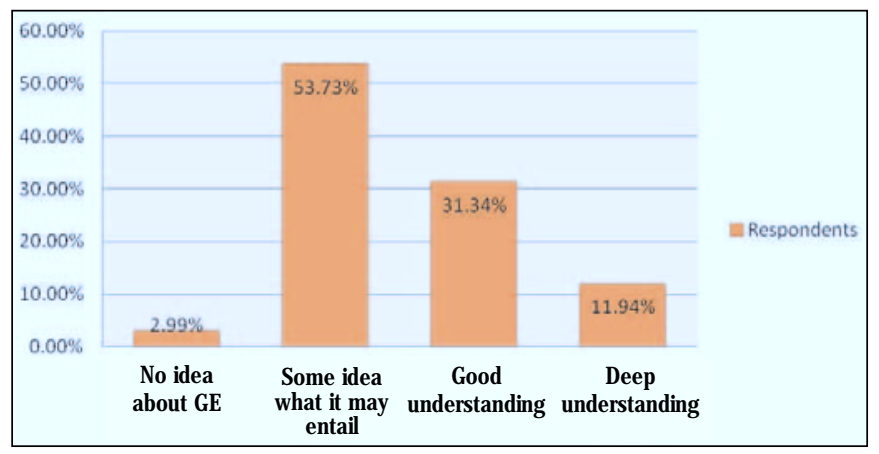

Fig 2 : Respondents level of understanding on GE

Our study showed media had quite an influence on how people got introduced to GE. How Science Fiction Movies or Novels (26.79\%), other media sources portrays the unethical and ethical issues of GE can influence the judgment of these respondents. While a high percentage of respondents also learnt about GE from School or University $(25 \%)$ which shows they might have studied the subject or related subject or took part in an activity of the school where they learnt about it. (2.68\%) of the respondents had skipped this question as they had no idea about GE before. Respondents who learnt from other sources specified they got introduced to GE through Doctors or Hospital counselors who diagnosed the inherited disease they suffer from (Fig 3).

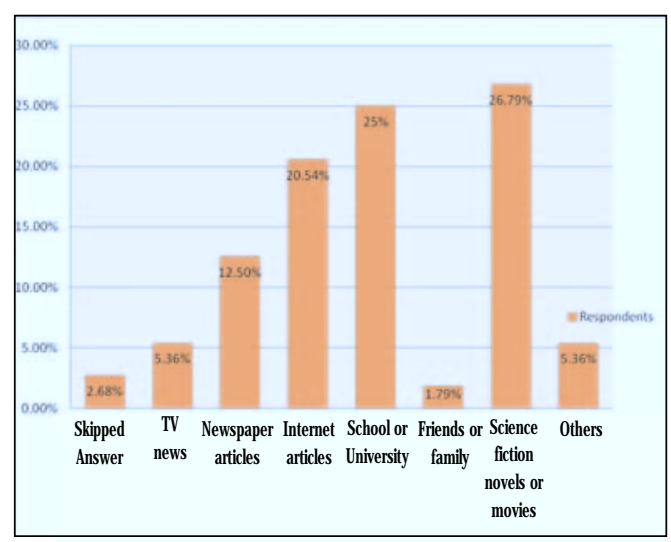

Fig 3 : How respondents get introduced to the term GE (had multiple answers)

The percentage of respondents who studied GE or its related subjects (47.76\%) and the ones who did not $(52.24 \%)$ were found almost equal in this study (Fig 4).

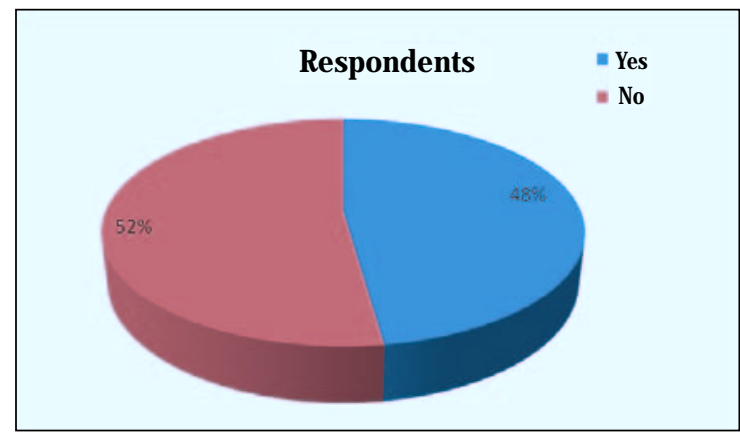

Fig 4: Respondents ever studied on GE or its related subjects

This study showed that the majority of the people had accepted GE. Among them $32.35 \%$ of people found the modification of genes unethical but necessary and $30.88 \%$ of people found it Ethical and very useful (Fig 5). When asked in the survey if they would use medicine made from genetically modified bacterium the $73.13 \%$ of people responded with a yes. When used for a good cause GE is morally acceptable to people (Fig 6).

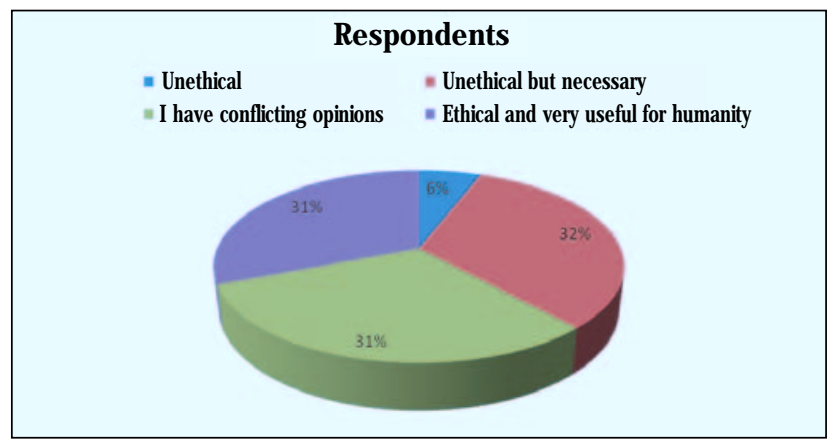

Fig 5 : opinion on ethical issuse of GE 


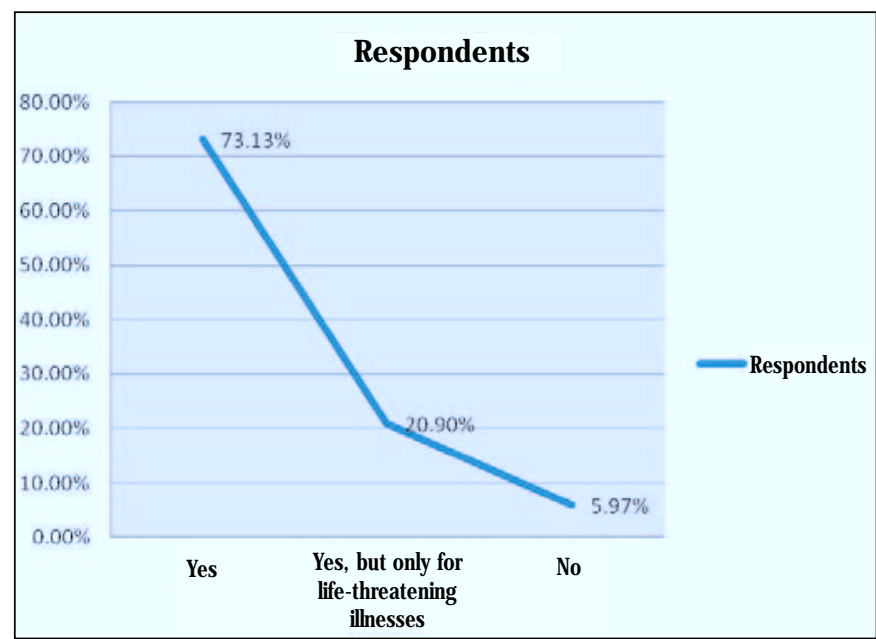

Fig 6 : Whether the respondents use a medicine made by genetically engineered bacterium? (eg. Insulin production for the treatment of diabetic patients)

This study data suggests that the majority of the respondents think GE will be more accepted in the society with time. While a minor portion of respondents are still skeptical about GE. On a Likert scale (17.91\%) of respondents 'Strongly agrees' to the statement. (55.22\%) of respondents 'Agrees' to the statement. (13.43\%) of the respondents neither agreed nor disagreed. (7.46\%) of respondents opposed the statement. The rest of the $(5.97 \%)$ respondents 'Strongly disagrees' with the statement (Fig 7)

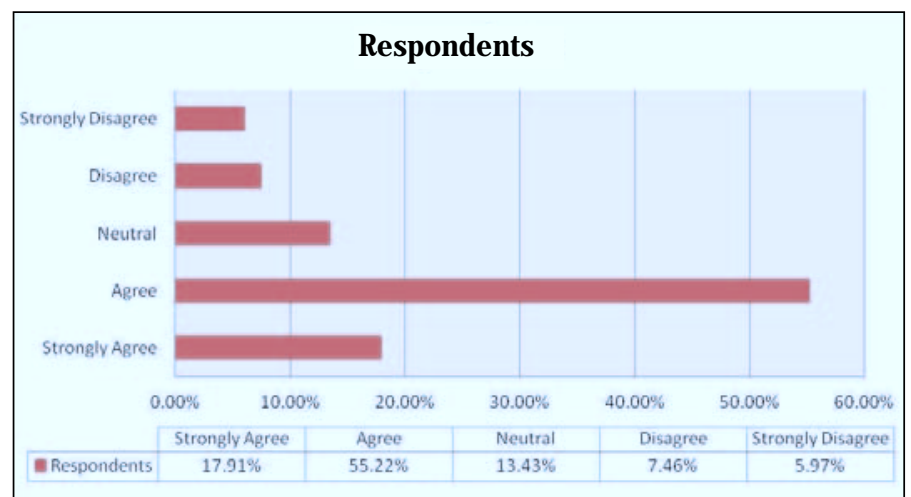

Fig 7: Time is proof that most of the arts that were once considered to be witchcraft and dark magic were later understood as scientific and logicallike this respondent feeling on the effect of time regarding GE

Do you feel that time will have the same effect on the mentality of the people when it comes to genetic modifications?

Most of the respondents (56.27\%) felt Science was not communicated to them in an understandable way. It would also point out why people rely more on media (a more understandable ground) than the other sources (Fig 8)

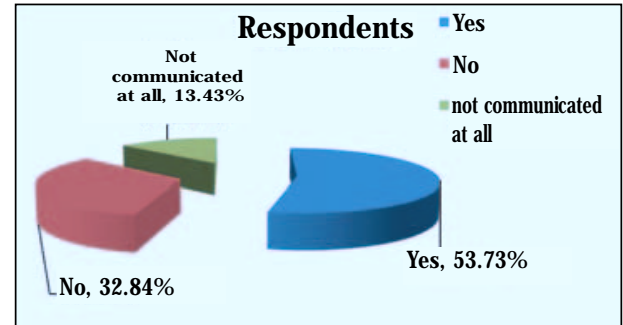

Fig 8: New advances in science are communicated to the respondents in an understandable way
About the public opinion on law enactment on GE and monitoring by governmental influence this research data also showed that $68.66 \%$ of the respondents think GE should be controlled by some sort of governmental influence. People think that for this ever changing and advancing Science should have a regulatory system by the government (Fig 9).

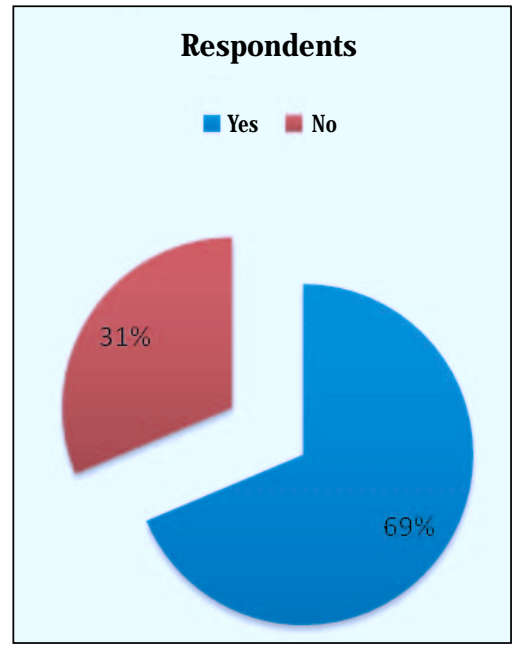

Fig 9: whether GE required control by some sort of governmental influence

\section{Discussion}

Genetic engineering is a difficult and very modern issue. Modern science has made possible the transfer of genes from one species to another. Debate about whether this should be allowed is becoming quite heated. The problem solving aspect of science is dependent entirely on the ability to explore the unknown in a variety of ways. As Charles Sanders Pierce stated, "There is one thing even more vital to science than intelligent methods; and that is, the sincere desire to find the truth, whatever it may be," However, getting into any conclusion about the acceptance of GE in the society through research can be just as difficult, deepening that sincere desire.

GE has become one of the most controversial topics in Science for the last decade as it became an integral part of engineering, biotechnology, and economics. Its ethical issues concern the geneticists as well as general people also. One of the main reasons of this study is that we wanted people to be aware of the real picture and also to get the insight of other people on GE.

In this study 67 respondents from all the seven continents, all of them were above 18 years of age were participated.

Hoban and Thomas (1998) in their research on 'Studies on trends regarding public awareness and understanding of agricultural biotechnology in the US' showed that only one-third of consumers in the US have heard or read about biotechnology. The trend, however, changed in 1997 when 'Dolly, the sheep', was widely publicized by the media. Survey results in the US and in Japan showed that increasing level of awareness leads to increasing consumer acceptance of agricultural biotechnology products. ${ }^{2}$ William K. Hallman et al (2003) found in their research that $43 \%$ had heard or read "not much" or "nothing at all" about genetic engineering or biotechnology, while $45 \%$ had heard or read "some." Only $12 \%$ had heard or read a "great deal" about it. ${ }^{3}$ Both of these research were done in USA. But this research was done globally and recently so it's data differ from the previous researches.

In our study it was found that most of them were aware of GE i.e., $53.73 \%$ had at least 'some idea' about what genetic engineering is, $31.34 \%$ of the respondents claimed to know 'what it is', $11.94 \%$ of the respondents said they had a 'deep understanding of the field' and only 2.99\% respondents said they had 'never been introduced' to GE.

This study showed that media had quite an influence on how people got introduced to GE. 'Science fiction novels or movies' was the highest chosen source $(26.79 \%)$ of getting introduced to GE and a high 
percentage of respondents (25\%) also learnt about GE from School or University. Next is from internet articles another $(20.54 \%)$. While Respondents who learnt from other sources specified they got introduced to GE through Doctors or Hospital counselors who diagnosed the inherited disease they suffer from.

Cleofe S.Torres et al (2006) also found more or less similar experience i.e. the main sources of information on biotechnology were the mass media (radio, television and newspaper) and interpersonal sources (friends, relatives, neighbors, experts and professionals), Even if majority of the respondents indicated some trust in websites, most of the respondents did not use the internet as an information source. This is interesting to note since advancements in technology would usually lead one to think that many stakeholders would take advantage of websites as an information source, especially since most of them were highly literate. Science-related sources such as NGOs, books and agricultural biotechnology companies were insignificant information sources on biotechnology as evidenced by the high number of respondents who did not use these information sources during the last two months. ${ }^{4}$

For this discussion, we also collected internet based survey from the site- Debate.org [link to the question-(http://www.debate.org/ opinions/is-genetic-engineering-ethical) $]^{5}$

They debated if GE is ethical- where $49 \%$ said yes and $51 \%$ said No. However our study had a different result with the view that- most of the respondents find GE ethical and very useful for humanity.

In 1976 Professor George Wald, Noble Laureate, was being skeptical about GE and proclaimed in his book The Dangers of Genetic Engineering that "Just as the success of a corporate body in making money need not set the human condition ahead, neither does every scientific advance automatically make our lives more meaningful". 6

The studies done over the years in 2005, 2008, 2007 and 2013 proved how beneficial GE was to the human kind. From the following articles we found- Bacteria were the first organisms to be modified in the laboratory, due to their simple genetics. ${ }^{7}$ These organisms are now used for several purposes, and are particularly important in producing large amounts of pure human proteins for use in medicine. ${ }^{8}$ Genetically modified bacteria are used to produce the protein insulin to treat diabetes. ${ }^{9}$ Similar bacteria have been used to produce biofuels. ${ }^{10}$ Clotting factors to treat haemophilia, ${ }^{11}$ and human growth hormone to treat various forms of dwarfism.12, 13

In this study one of our questions was Time is proof that most of the arts that were once considered to be witchcraft and dark magic were later understood as scientific and logical. Do you feel that time will have the same effect on the mentality of the people when it comes to genetic modifications?' Most of the (55.22\%) respondents 'Agrees' to the statement. The reference articles shed light on how GE is being used for the greater good and people's mentality is changing over time. As we know Institutions that conduct certain types of scientific research must obtain permission from government authorities and ethical committees before they conduct any experiments. Universities and research institutes generally have a special committee that is responsible for approving any experiments that involve genetic engineering.

Our study also showed that $68.66 \%$ of the respondents think GE should be controlled by some sort of governmental influence. People think that for this unpredictable and rapidly advancing Science should have a regulatory system by the government. In this study we wanted to analyze if people think GE should be controlled by law. In the following references we have found that law has been enacted in different countries which vary depending on the controlling authority.

For a genetically modified organism to be approved for release in the USA, it must be assessed by the Animal and Plant Health Inspection Service (APHIS) agency within the US Department of Agriculture (USDA) and may also be assessed by the Food and Drug Administration (FDA) and the Environmental protection agency (EPA), depending on the intended use of the organism. ${ }^{14}$ Common Market for Eastern and Southern Africa (COMASA) is responsible for assessing the safety of genetically modified organism (GMO)s in most of Africa, although the final decision lies with each individual country. ${ }^{15}$ India and China are the two largest producers of genetically modified products in Asia. ${ }^{16}$ The Office of Agricultural Genetic Engineering Biosafety Administration (OAGEBA) is responsible for regulation in China, ${ }^{17}$ while in India it is the Institutional Biosafety Committee (IBSC), Review Committee on Genetic Manipulation (RCGM) and Genetic Engineering Approval Committee (GEAC). ${ }^{17}$

\section{Conclusion}

This study has provided a brief idea about the mental attitude or psychology of the respondents regarding the acceptance of GE in the society. From the data of this study it also showed that majority of the people are influenced by the media- how Science Fiction Movies or Novels, other media sources portrays the unethical and ethical issues of GE , which can influence the judgment of the people. Even though genetic enhancement in humans is still limited to science fiction, it is a controversial issue as it might affect how people speculate GE would progress.

Science should raise ethical issues by introducing the "new" and ethical issues should influence science, thus creating a healthy tension between genetic engineering research and ethical issues and boundaries, and hopefully avoiding potential harmful consequences of unmonitored science through this balanced approach.

\section{Limitation}

We have chosen to do the survey on the sample of representative all over the world to make it as neutral as possible. It would have been more accurate if the number of respondents were much higher.

\section{References}

1. The European Parliament and the council of the European Union (12 March 2001). Directive on the release of genetically modified organisms (GMOs) Directive 2001/18/EC ANNEX I A. Official J ournal of the European Communities. p. page 17

2. Hoban, Thomas. (1998). Trends in Consumer Attitudes About Agricultural Biotechnology AgBioForum, 1(1), 3-7. http://www.agbioforum.org

3. William K. et all (2003, October) Public perceptions of genetically modified foods: A National Study of American Knowledge and Opinion.Food Policy Institute $\bullet$ Cook College Rutgers, The State University of New Jersey. Retrieved from http://www. foodpolicyinstitute.org

4. Cleofe S.(march 2006) Public Understanding and Perception of and Attitude Towards Agricultural Biotechnology in the Philippines, International Service for the Acquisition of Agri-biotech Applications (ISAAA) SEAMEO Regional Center for Graduate Study and Research in Agriculture (SEARCA) College of Development Communication, University of the Philippines Los Baños (CDC-UPLB).

5. Is genetic engineering ethical? (n.d). Retrieved from http://www. debate.org/opinions/isgenetic-engineering-ethical

6. W. George (1976), The Dangers of Genetic Engineering, p.45.

7. Melo, Eduardo O.et all (2009); Rumpf, Rodolpho (2007). "Animal transgenesis: state of the art and applications". J. Appl. Genet. 48 (1): 47-61. doi:10.1007/BF03194657.

8. L. Benjamin et all; (January 2008). "Protein therapeutics: a summary and pharmacological classification". Nature Reviews Drug Discovery. A guide to drug discovery 7 (1): 21-39. doi:10.1038/nrd2399. PMID 18097458

9. W. Gary (April 2005). "Therapeutic insulins and their large-scale manufacture". Appl. Microbial. Biotechnology. 67 (2): 151-159. doi:10.1007/s00253-004-1809-x. PMID 15580495.

10. Summers, Rebecca (24 April 2013) Bacteria churn out first ever petrol-like biofuel, New Scientist.

11. Pipe, Steven W. (May 2008). "Recombinant clotting factors". Thromb. Haemost. 99 (5) 840-850. doi:10.1160/TH07-10-0593. PMID 18449413.

12. Bryant et all (2007). "Recombinant growth hormone for idiopathic short stature in children and adolescents". Cochrane Database System Rev (3): CD004440. doi:10.1002/14651858.CD004440.pub2.PMID 17636758.

13. Baxter et all(2007). "Recombinant growth hormone for children and adolescents with Turner syndrome". Cochrane Database System Rev (1): CD003887. doi:10.1002/14651858.CD003887.pub2. PMID 17253498.

14. (2001). Guide to U.S. Regulation of Genetically Modified Food and Agricultural Biotechnology Products. The Pew Initiative on Food and Biotechnology. Washington, DC: The Pew Charitable Trusts..

15. ISAAA. (2007). Global Status of Commercialized Biotech/GM Crops: 2007. Retrieved from http://www.isaaa.org/resources/publications/briefs/37/ executivesummary/default.html

16. TNAU Agritech portal. (n.d). Bio Technology:: GM Crops. Retrieved from http://agritech.tnau.ac.in/bio-tech/biotech gmcrop gmregulation.html

17. AgBioForum 5(4): Agricultural Biotechnology Development and Policy in China 